\title{
A INCOMUNICABILIDADE DO SER DO LOGOS PERSUASIVO: UMA LEITURA FILOSÓFICA DA OBRA “ELOGIO DE HELENA”, DE GÓRGIAS DE LEONTINI
}

\section{THE INABILITY OF BEING LOGOS PERSUASIVE: A PHILOSOPHICAL READING OF THE WORK "HELEN OF PRAISE", GORGIAS OF LEONTINI}

Arlaton Luiz Soares de Oliveira*

\section{Introdução}

Com o advento sofista no século $\mathrm{V}$ a. C., a concepção realista e dogmática de que a atribuição afirmativa ou negativa estabelecida por um juízo sobre os fatos concretos constitui o real, tal como é expresso pela linguagem, começa a ser questionada. Em consequência disso, a ligação entre o conceito e a própria realidade, que garante o critério de verdade, diante de uma situação de decisão em assembleia, onde muitas opiniões se chocam, é posta em xeque com o alvorecer da democracia ateniense.

A democracia nesse período repousava-se sobre os princípios da isonomia (igualdade de direitos) e isegoria (igualdade de palavra), que garantia a participação de todos os considerados cidadãos nas decisões da cidade.

A arte retórica assume um lugar privilegiado na ágora grega. Nesse ambiente aberto, discursos de hábeis oradores ecoaram e mobilizaram cidadãos em torno de uma ordem do dia, no qual se estabelecia leis e se julgava sob o critério da maioria. Toma-se consciência do poder existente no discurso persuasivo, o que requer a demanda pelo serviço de profissionais que se dedicassem ao ensino do cidadão preparando-o ao fazer político.

Grandes nomes surgem como Protágoras de Abdera, Hípias de Elis, Pródico de Ceos, Trasímaco da Calcedônia, Górgias de Leontini e tantos outros, em atividade na Atenas democrática de Péricles do Século V a. C. Os sofistas ofereceram à democracia grega uma formação eficiente que possibilitaria aos homens o ingresso na carreira política e na vida pública em geral. "Mas como a finalidade principal continuava sendo a de preparar homens para uma carreira na política, não é de se surpreender que uma parte essencial da educação oferecida fosse treinar para a arte do discurso" (KERFERD, 2003, p. 35).

\footnotetext{
${ }^{*}$ Licenciado em Filosofia pelo instituto Santo Tomás de Aquino (BH/MG), graduando em Teologia pelo mesmo Instituto. E-mail: arlatonluiz@hotmail.com.
} 


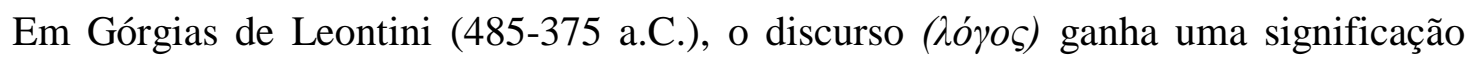
ligada à persuasão performativa, pois possui o poder de portar em si o mundo, mas não pela faculdade mimética, ou seja, como um mero reflexo da realidade. Esse poder é um poder criador, capaz de modificar as opiniões referentes a fatos, mesmo que estes sejam conhecidos pelos ouvintes. Ele repousa-se sob uma concepção de que o discurso não possui a obrigatoriedade de dizer o mundo em si mesmo.

\section{0 elogio de helena}

O "Elogio de Helena" ilustra a relação do poder do logos situado no hiato entre o mundo em si e a percepção que se tem dele, que possibilita modificar a opinião acerca da figura mitológica de Helena, considerada como a causadora da querela mítica entre gregos e troianos.

Este elogio constitui um modelo de exercício retórico a ser aprendido pelos discípulos de Górgias. Ele constitui um dos três gêneros retóricos descritos por Aristóteles em sua "Arte Retórica" e é por ele denominado gênero epidítico (epideixis). O elogio epidítico, em seu sentido original, epideixis significa a "arte de 'mostrar' (deíknumi) 'diante' (epî), na presença de um público, de fazer mostra ou ostentação de.” (CASSIN; LOURAUX; PESCHANSKI, 1993, p. 38).

O papel dos discursos epidíticos constitui por intensificar e solidificar a adesão aos valores comuns do auditório. Esses valores às vezes não são formulados de forma clara na mente do público. Isso garante ao orador a possibilidade da organização dos valores em conceitos, a fim de possibilitar a transmissão desses, provocando emoções.

Entretanto, a empreitada gorgiana possui uma característica peculiar, pois para que o elogio da figura de Helena seja efetuado, faz-se mister que se modifique a impressão de uma visão sedimentada que toma a bela espartana como traidora e causadora da Guerra de Tróia. Pra tal intento, já no prólogo do Elogio, Górgias se propõe a inocentar Helena das graves acusações a ela correntemente direcionadas, "expondo" a verdade:

Eu, porém, pretendo - dando ao discurso alguma lógica - por um lado, fazer cessar a acusação sobre a que foi mal falada; por outro lado, demonstrar que os que a repreendem estão mentindo e expor a verdade [ou] fazer cessar a ignorância. (GÓRGIAS, 2009, p.1). 
Quatro silogismos hipotético-condicionais situam-se no "cerne" do discurso gorgiano. O primeiro se refere à coerção heteronômica advinda da vontade dos deuses em unir Helena a Páris. "Se foi, então, por causa do primeiro, o causador merece ser acusado, pois o ímpeto de um deus, por precaução humana, é impossível impedir.” (GÓRGIAS, 2009, p.2).

A segunda hipótese consiste na probabilidade do rapto de Helena por Páris, o que nesse caso, consistiria na inocência da esposa de Menelau.

O terceiro argumento expõe uma "doutrina" sobre o poder do logos persuasivo. Em primeiro lugar, Górgias apresenta o discurso como "um grande senhor que, por meio do menor e mais inaparente corpo, leva à cabo as obras mais divinas. Pois é capaz de fazer cessar o medo, retirar a dor, produzir alegria e fazer crescer a compaixão.” (GÓRGIAS, 2009, p. 3). Nesse trecho é dado ênfase ao poder do logos que consegue produzir sentimentos em seus ouvintes. Isso pode ser percebido com a comparação que o texto faz entre discurso e poesia no tocante ao efeito emocional produzido por essas artes.

Outro atributo dado ao discurso é o poder mágico, advindo dos deuses que age sobre as almas entregues à opinião. Este feitiço do $\log o s$ tem grande poder sobre os homens, pois massageia a alma com palavras que trazem prazer, satisfação, com o intuito de alterá-la, modificá-la.

Na sequência do raciocínio, Górgias introduz uma palavra chave que será o "ponto de Arquimedes" argumentativo para a garantia do poder do discurso sobre a alma: a opinião.

A opinião, (doxa) é, de certo modo, escorregadia, claudicante, de modo que o logos tem poder de agir sobre a alma humana. Górgias prossegue com a proposição hipotética de que se a maioria dos homens é incapaz de recordar o que de fato aconteceu, ou de investigar o presente, ou de adivinhar o futuro, na maioria das questões, eles usam a opinião (doxa) como conselheiro para suas almas.

A doxa, contudo, não é confiável e pode fazer a pessoa tropeçar e cair, com consequências infelizes para si mesmas. Desse modo, o discurso é capaz de agir persuasivamente nessa opinião porque a opinião não é conhecimento e, por isso, é possível modificá-la. Górgias finaliza a consideração declarando a inocência de Helena e atribui ao logos que a persuadiu a culpa, por ludibriá-la a acreditar nas coisas ditas e concordar com os atos feitos.

A última hipótese se refere à sedução do amor que entorpece a alma. Górgias salienta a ligação do amor com a vista, ou seja, com as impressões sensoriais que temos no instante de um contato visual com seres ou objetos (no caso, um contato visual de Helena com Páris); 
impressões muitas vezes perigosas, pois podem omitir os aspectos negativos do que se apresenta diante de nós e, assim, enganar o olhar.

Górgias estabelece uma separação entre o mundo em si e a percepção que se tem dele. "Pois as coisas que vemos têm uma natureza, não a que nós queremos, mas a que calhou a cada uma; por meio da visão a alma é marcada também em seus modos" (GÓRGIAS, 2009, p. 5).

O poder que o amor tem sobre a alma é impressionante, comparado ao poder da vontade divina, "se o que é deus tem o divino poder dos deuses, como o mais fraco seria capaz de o pôr para correr e se defender?" (GÓRGIAS, 2009, p. 7).

Ao final do mesmo argumento, Górgias dá uma curiosa definição do amor, como "uma doença humana e um desconhecimento por parte da alma", de tal modo que se ela apaixonou-se "não se deve imputar como erro, mas se deve julgar como infortúnio". (GÓRGIAS, 2009, p. 7).

É interessante notar o término do discurso. Assim como no prólogo, Górgias fornece ao ouvinte seu duplo objetivo: "dissipar a injustiça da reprimenda e a ignorância da opinião". Por não ser conhecimento, a opinião não é estável e nem se fundamenta em bons argumentos sustentados na "verdade" ou na probabilidade mais plausível.

Ora, como é possível haver opiniões errôneas, ignorantes, se os fatos são inquestionáveis? Helena deixou seu esposo Menelau e uniu-se a Páris, em Tróia. A existência da opinião, e por sua vez, de opiniões que sejam falsas, ou mais ou menos plausíveis, demonstra que a relação entre o pensamento, o discurso e os fatos não é das mais simples.

Exige um certo grau de organização e reorganização do fato em pensamento e este por sua vez em palavras. O poder do logos se caracteriza neste processo de organização, de certo “jogo" de palavras que, se bem articuladas, garantem a adesão do auditório à ideia apresentada. Sob essa ótica, é possível compreender a última frase de seu discurso: “(...) quis escrever o discurso, por um lado, como um elogio de Helena, por outro lado, como um brinquedo." (GÓRGIAS, 2009, p. 7).

\section{A incomunicabilidade do ser}

A probabilidade da inocência de Helena abre caminho para a reflexão sobre a relação entre os fatos concretos (mundo), percepção e interpretação do mundo (pensamento) e representação/expressão do mundo pela linguagem. Essa relação é trabalhada de modo mais aprofundado no tratado "Sobre o Não-ser". 
Nesse tratado, ao ser aberto uma separação entre as instâncias do mundo, pensamento e linguagem, aponta que o logos não pode ser reflexo, imitação da natureza das coisas, e muito menos expressar efetivamente a esfera do pensamento. A palavra gorgiana é distinta das instâncias do mundo e do pensamento e, por isso, não pode revelá-las objetivamente.

Górgias insere a incomunicabilidade do ser por meio de seu "Tratado do Não-Ser", também intitulado "Sobre a natureza". Nesse tratado há três teses fundamentais que podem ser assim descritas: "Nada é, se fosse não poderia ser pensado e se pensado, não poderia ser comunicado".

A teoria da Incomunicabilidade do ser pode ser encontrada parafraseada em dois textos que chegaram até os dias atuais: uma em Sexto Empírico, em sua obra "Contra Matemáticos" e outra, em uma obra erroneamente atribuída a Aristóteles, denominada "Sobre Melisso, Xenófanes e Górgias" que comumente é abreviada por MXG. Nesta comunicação será usada a obra MXG.

\section{A inexistência do ser}

No texto MXG, a primeira tese é anunciada da seguinte forma: "Nem ser nem não-ser é" (PSEUDO ARISTÓTELES apud DINUCCI, 2008, p. 199).

O modo como Górgias argumenta para justificar essa posição é de certo modo confusa ao um primeiro contato, pois o verbo "ser" usado na argumentação é relacionado ao seu sentido existencial e predicativo. Existencial, quando está ligado as expressões Ser e Não-Ser e predicativo quando está como verbo de ligação entre uma forma e outra.

Se, com efeito, o não-ser é não-ser, o-que-não-é em nada seria menos que o-que-é. Pois, tanto o-que-não-é é algo-que-não-é, quanto o-que-é [é] algo-que-é, de modo que as coisas em nada mais são do que não são. Se, no entanto, o não-ser é, o ser, a sua antítese, não é, diz ele. Se, com efeito, o não-ser é, convém ao ser não ser (PSEUDO ARISTÓTELES apud DINUCCI, 2008, p. 199).

O que Górgias pretende é emparelhar as opções para o Ser e o Não-Ser de modo que, se são distintos, se tornam a mesma coisa, pois identificam-se quanto ao ser. O Ser e o NãoSer têm em comum o ser. Se o Não-Ser é o inexistente, ele é alguma coisa, por isso iguala-se ao Ser.

Górgias, ao considerar o Não-ser como ser, faz de seu oposto, o Ser, se tornar o NãoSer. E isso é absurdo a consideração de coisas opostas como iguais. Ao fazer isso, a 
consequência é inevitável: Ao equiparar o Não-Ser com o Ser o nada surge como resultado. Nada é.

Portanto, nessa primeira tese, a noção de ser porta em si mesma contradições. Essas contradições tornam qualquer discurso fadado à anulação e ao fracasso, se pretende abarcar em si mesmo o mundo, o ser das coisas.

\section{A incognoscibilidade do ser}

No texto MXG, a segunda tese é apresentada da seguinte forma: "Górgias diz que se é, é incognoscível". Kerferd atribui como principal interesse dessa segunda tese a "maneira como ele abre um contraste, de fato um fosso, entre atos mentais cognitivos (pensamentos, percepções, etc.) e os objetos que eles conhecem ou pretendem conhecer" (KERFERD, 2003, p. 166).

A argumentação dessa segunda tese traz alusão à argumentação do poema parmenídico "Sobre a natureza", que declara que ser, pensar e dizer são uma só coisa. Essa é a via da verdade - alétheia - e a da doce persuasão que a acompanha. Já a via da opinião não pode ser percorrida porque não pode ser pensada nem dita.

Parmênides estabelece a identificação entre o que é o ser, o que é o pensar e o que é o dizer, de modo que "o que é" é o que pode ser pensado e dito, enquanto que "o que não é" não pode ser pensado nem dito.

Entretanto, Górgias segue uma corrente contrária a Parmênides, distanciando o pensar do ser, se por ventura esse ser fosse. Ele começa dizendo que se adotarmos a posição do ser sendo, todas as coisas pensadas devem necessariamente ser, independente se são Ser ou NãoSer:

Com efeito, é necessário que todas as coisas pensadas sejam, e o-que-não-é, já que não é, não pode ser pensado. No entanto, sendo assim, ninguém diria nada falso, diz [Górgias], nem mesmo se diz que carros de guerra combatem no mar. Pois, neste caso, todas as coisas seriam. E, com efeito, por causa disto, as coisas vistas e as coisas ouvidas serão, porque cada uma delas é pensada (PSEUDO ARISTÓTELES apud DINUCCI, 2008, p. 200).

O fosso entre ser e pensar é aberto quando Górgias prossegue sua explanação fazendo recurso à visão, pois somente a visão pode ser critério para a visão e não o pensamento. $\mathrm{O}$ estatuto de existência das coisas não pode ser dado pelo pensamento, se o que ocorre foi um contato sensorial, que é distinto do pensamento. 


\begin{abstract}
Mas, se não é assim, e, do mesmo modo que as coisas que vemos, em nada mais são porque as vemos, assim as coisas que vemos não mais são pensadas porque as vemos, (e, com efeito, do mesmo modo que tanto muitos aí vêem estas coisas quanto muitos estas coisas pensassem), porque, portanto, seria mais evidente que tal coisa é? Mas não é evidente que tipo de coisas é verdadeiro. De modo que, se tais coisas também são, para nós seriam incognoscíveis (PSEUDO ARISTÓTELES apud DINUCCI, 2008, p. 200).
\end{abstract}

Esse argumento é retomado e melhor explicitado na terceira tese do tratado no qual se argumenta, que se alguma coisa é e pode ser pensada não pode ser comunicada ao interlocutor.

\title{
60 ser não comunicável
}

Nesta terceira tese, há o recurso argumentativo da percepção sensorial que tem por objetivo dar suporte à incomunicabilidade do ser. No tratado MXG a linha argumentativa segue à argumentação da segunda tese, da incognoscibilidade do ser, fazendo a diferenciação das percepções sensoriais do pensamento e da palavra.

Não podemos experienciar uma percepção própria de um sentido através de outro sentido. O logos como é algo distinto dos sentidos, não pode comunicar coisa alguma percebida pelos sentidos. Ele não pode conter, como diz Aristóteles, a essência das coisas em si mesmo. Ele comunica somente a si mesmo.

Mas há algo que se deve levar em conta. O logos, o discurso, nasce das impressões sensíveis. A cada impressão sensorial relaciona-se a um tipo de discurso correspondente a essa impressão. "O logos não tem a função de exibir o objeto externo, é o objeto externo que nos fornece informação acerca do (significado do) logos" (KERFERD, 2003, p. 168).

Górgias ao separar os sentidos, o pensamento e o logos, também considera que eles não se comunicam entre si. Mas ainda surge a questão sobre a possibilidade de transmitir a experiência particular sensorial de um indivíduo a outro de forma objetiva pelo discurso.

O Tratado MXG termina a paráfrase de Górgias apontando a incomunicabilidade do ser sob três justificativas. A primeira é que para que a comunicação de uma experiência de um indivíduo fosse dada a outro, seria impossível, pois "não é possível o mesmo estar simultaneamente em numerosas pessoas, pois um seria dois" (PSEUDO ARISTÓTELES apud DINUCCI, 2008, p. 201). 
A segunda é que mesmo se acontecesse de a mesma coisa ser pensada simultaneamente, "seria um, mas não dois". A terceira é que nem mesmo o sujeito experimenta a mesma sensação do mesmo jeito nos diferentes sentidos.

\begin{abstract}
No entanto, nem um mesmo homem parece perceber coisas semelhantes ao mesmo tempo, mas coisas diferentes pela audição e pela visão, e diferentemente tanto agora quanto antes, de modo que dificilmente alguém perceberia uma mesma coisa idêntica a uma outra. Assim, nada é; se é algo, é tanto porque as coisas não são as palavras quanto porque ninguém tem no espírito a mesma coisa que outra pessoa (PSEUDO ARISTÓTELES apud DINUCCI, 2008, p. 201).
\end{abstract}

Com a incomunicabilidade do ser de Górgias parece ser improvável ao logos transmitir o mundo. Ele transmite nada, pois o ser não é, e se fosse não poderia ser pensado ou comunicado. Esse posicionamento traz certo ceticismo, que a primeira vista pode causar espanto aos que entram em contato com o pensamento de Górgias.

Mas deve-se levar em conta o diálogo que essa teoria faz com Parmênides, com os demais eleatas e também com os pluralistas, como seu mestre Empédocles. Uma teoria como essa demonstra a impossibilidade do discurso, da palavra de conter o real, pois ele nada é. E onde nada é, tudo é possível. Nesse aspecto, o logos se abre para uma nova perspectiva, ele ganha autonomia em relação ao mundo, pois não possui a obrigatoriedade de dizê-lo e sim de mostrar a si próprio, mesmo sendo suscitado pela sensibilidade.

No Elogio de Helena há uma interessante intuição sobre o poder do discurso que modifica as opiniões referentes aos fatos, mesmo que estes sejam conhecidos pelos ouvintes. Esse poder repousa-se sob uma concepção de que o discurso não possui a obrigatoriedade de dizer o mundo em si mesmo. Nesse sentido, o logos porta uma liberdade expressa em suas inúmeras possibilidades de formular "mundos".

Essa formulação é entendida numa dupla instância: interpretação e expressão. A interpretação no Elogio de Górgias advém da vivência particular, da experiência sensorial, que "per si" não garante a verdade do mundo. O que existe é uma forma particular de sentir o mundo. Desse modo, nota-se, um hiato entre o mundo em si e a percepção que se tem dele.

A expressão por meio da linguagem é rica de possibilidades. Existem diversos modos de exprimir um juízo, uma constatação sobre um determinado fato ou objeto. Em Górgias, a construção de um discurso possui um modo próprio cujo intuito é dar prazer. "Aquele que, então, e por que e como saciou o amor tomando Helena, não direi; pois o dizer aos que sabem coisas que sabem tem credibilidade, mas não traz deleite" (GÓRGIAS, 2009, p. 2). O discurso 
gorgiano possui a pretensão de, graças à incomunicabilidade do ser, convencer qualquer um de qualquer coisa, criando e recriando realidades, modelando a opinião.

\section{Referências}

ARISTÓTELES. Arte retórica e arte poética. Tradução Antônio Pinto de Carvalho. São Paulo: Difusão Européia do Livro, 1959.

DINUCCI, Aldo. Paráfrase do MXG do Tratado do Não-Ser de Górgias de Leontinos: apresentação e tradução. Trans/Form/Ação, Marília, v.31, n.1, maio/ago. 2008. Disponível em:< http://www.scielo.br/pdf/trans/v31n1/v31n1a11.pdf>. Acesso em: 2 set. 2012.

FERREIRA, José Ribeiro. A Grécia antiga: sociedade e política. Lisboa: Edições 70, 1992.

GORGIAS. Elogio de Helena. Tradução Daniela Paulinelli. Belo Horizonte: Anágnosis, 2009. Disponível em: <http://anagnosisufmg.blogspot.com/2009/10/elogio-de-helenagorgias.html>. Acesso em: 12 abr. 2011.

GÓRGIAS, Testemunhos e Fragmentos. Tradução Manuel Barbosa e Inês de Ornellas e Castro. Lisboa: Edições Colibri, 1993. (Mare Nostrum).

GUTHRIE, W. K. C. Os sofistas. Tradução João Resende da Costa. 2. ed. São Paulo: Paulus, 2007.

HADOT, Pierre. O que é a filosofia antiga? São Paulo: Loyola, 2004.

KERFERD. George Briscoe. O movimento sofista. Tradução Margarida Oliva. São Paulo: Loyola, 2003.

MOSSÉ, Claude. Atenas: a história de uma democracia. Brasília: UnB, 1979.

MOURA, Carlos Soares de. Grécia Antiga: esquemas e textos. Belo Horizonte: Universidade Católica de Minas Gerais. 1981. (Cadernos UCMG, n.7. Série História).

PLATÃO. Diálogos IX: Teeteto - Crátilo. Belém: Universidade Federal do Pará, 1973.

PLATÃO. Górgias. 5. ed. Lisboa: Edições 70, 2004.

ROBINET, Jean-François. O tempo do pensamento. São Paulo: Paulus, 2004. 